ARTIGO

\title{
As experiências nos espaços-tempos da escola sob o olhar de uma criança com Transtorno do Espectro do Autismo
}

\author{
Lyanny Araujo Francês' (D) \\ Amélia Maria Araújo Mesquita"
}

RESUMO

$\mathrm{O}$ artigo visa a discutir a escola a partir do olhar da criança acerca das experiências vivenciadas nos espaços-tempos da escola. O campo empírico se constituiu utilizando instrumentos metodológicos da etnografia, à luz do referencial da Sociologia da Infância, tendo como sujeito uma criança com Transtorno do Espectro do Autismo (TEA). Para a sistematização, fizemos uso da análise de conteúdo, que originou as categorias da investigação. Identificamos que a criança com TEA irroga sentido à medida que vive tais experiências, procurando condutas dissímeis para relacionar-se com seus pares e com adultos, bem como para desconstruir regras preestabelecidas nos espaços-tempos escolares. Assim, sobressai a premência da ausculta da criança em suas múltiplas formas de expressão, a fim de contribuir para a efetivação de práticas educativas assentes em saberes que a respeitem em seus traços geracionais, rompendo com os modos lineares de pensar a estrutura organizacional dos espaços-tempos da escola.

\section{PALAVRAS-CHAVE}

infância; experiência(s); inclusão escolar. 
EXPERIENCES IN A SCHOOL'S SPACE-

TIME FROM THE PERSPECTIVE OF A CHILD

\section{WITH AUTISM SPECTRUM DISORDER}

\section{ABSTRACT}

This paper aims at discussing the school from the child's point of view by means of this child's experiences in the school's spaces-times. The empirical field was constituted using methodological instruments of ethnography, based on the Sociology of Childhood, having as a subject a child with Autism Spectrum Disorder (ASD). Content analysis that originated research categories was used. Children with ASD irritate meaning as they live such experiences, looking for dissimilar conducts to relate to their peers and adults, as well as to deconstruct pre-established rules in the school's time-spaces. Thus, there is an urgency of auscultation of the child by means of their multiple forms of expression, in order to contribute to the effectiveness of educational practices based on knowledge that respects them in their generational traits, breaking with the linear ways of thinking the organizational structure of the school's spaces-times.

\section{KEYWORDS}

childhood; experience(s); school inclusion.

\section{LAS EXPERIENCIAS EN EL ESPACIO-TIEMPO DE LA ESCUELA BAJO LOS OJOS DE UN NIÑO CON TRASTORNO DEL ESPECTRO AUTISTA}

\section{RESUMEN}

El artículo tiene objetivo discutir la escuela desde la perspectiva del niño sobre experiencias en los espacios-tiempos escolares. El campo empírico se constituyó con instrumentos metodológicos de etnografía, la luz del marco de la Sociología de la Infancia, teniendo como sujeto un niño con Trastorno del Espectro Autista (TEA). En sistematización, hicimos uso del análisis de contenido que originó las categorías de investigación. Identificamos que el niño con TEA irrumpe el significado mientras vive tales experiencias, en busca de conductas diferentes para relacionarse con sus compañeros y adultos, así como deconstruir reglas preestablecidas en los espacios-tiempos escolares. Así, es urgente la auscultación del niño en sus múltiples formas de expresión, y contribuir a la efectividad de las prácticas educativas basadas en el conocimiento que lo respeta en sus rasgos generacionales, rompiendo con las formas lineales de pensar la estructura organizativa de los espacios-tiempos escolares.

PALABRAS CLAVE

infancia; experiencia(s); inclusión escolar. 


\section{INTRODUÇÃO}

Neste texto, partimos do pressuposto do reconhecimento da criança como sujeito ativo que produz culturas infantis próprias (Corsaro, 2011; Sarmento, 2004, 2005), o que possibilita outras reflexões acerca das concepções de infância e da criança no âmbito educacional. Essa constatação concernente ao papel social da infância e, portanto, da criança como sujeito protagonista de sua história, impulsionou a materialização de investigações sobre essa categoria geracional e suas especificidades.

Associar esse pressuposto à discussão da inclusão educacional se coloca como um desafio e traz um conjunto de outras perspectivas para problematizar/ pensar/analisar a inclusão tendo como protagonista a criança com deficiência, o que possibilita ampliar a discussão sobre a escola e suas práticas.

Convém destacar, no entanto, que a educação inclusiva, ou, mais especificamente, a educação especial na perspectiva da educação inclusiva, tem sido objeto constante de análise de pesquisas de mestrado e doutorado. Em busca realizada no Catálogo de Teses e Dissertações da Coordenação de Aperfeiçoamento de Pessoal de Nível Superior (CAPES), referente aos estudos empreendidos nos anos de 2016 e 2017, usando como palavras-chave "educação especial-educação inclusiva", foi possível identificar um volume com mais de 28.747 produções.

A despeito desse volume de produção, Morais (2014) assevera que, apesar de as crianças terem sido objeto de análise, os estudos debruçaram-se a investigar sobre as crianças, e não com elas (Carmo Neto, 2000; Tonus, 2010; Melo, 2013), ou seja, investigaram a inclusão a partir do olhar dos professores, gestores, pais, entre outros, mas não ouviram o que têm a dizer as crianças com deficiência. Assim, tais pesquisas externaram reflexões dos adultos sobre a inclusão, e não a partir das vozes das crianças, não expressaram suas ideias de maneira genuína e, com isso, expuseram considerações de sujeitos outros, como professores, gestores ou pais, concernentes às experiências vividas pela criança no contexto da inclusão.

Considerando-se que falar da inclusão a partir das experiências da criança com deficiência valoriza o protagonismo desses sujeitos e tendo em vista que é fundamental ampliar o debate sobre os processos inclusivos a partir de investigações com as crianças, e não sobre elas, realizamos outro levantamento de pesquisas junto ao banco de teses da CAPES, usando agora as palavras-chave "criança-voz-inclusão", no qual constatamos que grande parte dos trabalhos conduziu a remates da área fonoaudiológica, com crianças com surdez ou afins, além de estudos específicos de profissionais da área médica sobre as pessoas com deficiência, fato que nos levou a ampliar o interstício de tempo em busca de estudos que desvelassem em seus resultados a voz da criança.

A partir do refinamento e considerando aquelas que adotaram a perspectiva teórico-metodológica da Sociologia da Infância, destacamos as pesquisas de Pereira (2011), Morais (2014), Maisatto (2014) e Herrera (2016), que se debruçaram em trazer a voz da criança com deficiência, exprimindo o que sente a partir de suas próprias manifestações. Esses estudos investigaram crianças com deficiência intelectual, física e múltipla, bem como autistas, e focaram em aspectos acerca do 
que pensam, sentem e falam essas crianças sobre o cotidiano escolar no contexto da inclusão, com o objetivo de compreender os sentidos atribuídos à escola.

Observamos que as pesquisas ressaíram a relevância em dar a palavra à criança, facultando a ela expressar-se a partir de sua própria linguagem — verbal ou não verbal. $\mathrm{E}$, ao tencionarem auscultar a criança, ainda que em número exíguo, consideraram a criança como sujeito que produz saberes inerentes a partir das interações que constrói tanto com seus pares quanto com o mundo adulto. Assim, tais pesquisas discorreram sobre a percepção que as crianças têm da educação infantil e o que pensam a respeito do processo de inclusão, as brincadeiras nas quais participam no cotidiano da escola, desvelando o modo como vivenciam e significam a instituição educativa e/ou o Atendimento Educacional Especializado.

Ressaltamos que, apesar de conseguirem transmitir a voz das crianças em seus desfechos, as pesquisas sinalizaram a relevância em ampliar os estudos com as crianças com deficiência sem, contudo, preterir os estudos que expressam as elocuções dos outros sujeitos envoltos no contexto da escola, tal como aqueles que se dedicam a abordar as políticas públicas de inclusão, posto que discutem as nuances implicadas no sistema educacional na perspectiva inclusiva.

Tal debate impulsionou o interesse pela escolha do objeto de estudo deste artigo, que tem como foco a ausculta de uma criança com Transtorno do Espectro do Autismo (TEA) a partir de suas múltiplas manifestações, de suas vivências cotidianas, evidenciando suas exiguidades - por conceber que é competente para falar, e que, portanto, tem muito a dizer sobre as experiências vividas nos espaços-tempos da escola. Ademais, as experiências infantis são fundamentais para entender de que forma a escola produz processos de significação e, portanto, dão pistas sobre o que temos produzido em nossas práticas e de que forma favorecem, ou não, processos de inclusão.

Nesse sentido, propomo-nos a refletir a respeito da inclusão no contexto da escola regular e elucidar que experiências são vivenciadas pela criança com TEA nos espaços-tempos da escola regular a partir de suas próprias manifestações.

\section{PENSANDO A EXPERIÊNCIA PUERIL}

Compreender os construtos sobre as experiências da infância e o saber subsequente logrados nas culturas de pares se faz primordial para alcance do objetivo deste texto. Para tanto, recorremos aos contributos da Sociologia da Infância, que compreende a criança como ator social e a infância como uma categoria socialmente construída para explorar a natureza e a variabilidade das experiências pueris (Corsaro, 2011; Sarmento, 2004, 2005).

A respeito da experiência infantil, optamos por perscrutar por meio dos intelectos de Benjamin (2002) e Bondía (2002), em razão da simetria existente entre as convicções desses estudiosos e os teóricos da Sociologia da Infância, no que tange à ideia de infância, ao tratamento outorgado à criança - cuja sapiência não desmerecem, e à singularidade de suas experiências, chamando a atenção para a postura adultocêntrica diante da infância. 
Nas reflexões dos autores supracitados, trata-se de processos que indiciam esforços da criança para apropriar-se do mundo e, assim, erigir seus modos de existência nas culturas de pares das quais participa. Ao discorrerem acerca da correlação entre experiência e o conhecimento advindo dela, salientam que as experiências infantis se apresentam dissemelhantes em relação às experiências dos adultos; logo, produzem conhecimentos e culturas igualmente distintos e independentes, enfatizando o pertencimento em categorias sociais dissemelhantes, indo ao encontro do que preconizam os pensadores da abordagem sociológica da infância.

Bondía (2002) sugere que passamos por distintos acontecimentos; desses, apenas aqueles que nos tocam, que nos marcam, podem ser considerados como experiências, menos pelo que nos proporcionam e mais pelo que nos ensinam. Walter Benjamin (2002) acresce ao afirmar que, cada vez mais, na sociedade, a criança passa por muitas coisas, porém, desses acontecimentos, a experiência é cada vez mais rara, quando considerada no sentido de algo que toca o ser humano. Ainda segundo o autor, o mais importante é permitir-se viver as experiências para abstrair o saber que ela experimenta, e não é o saber sobre qualquer coisa, mas um saber que resulta de um conhecimento advindo das experiências vividas.

Quando voltamos o olhar para as elucubrações dos pesquisadores da abordagem sociológica da infância (Corsaro, 2011; Sarmento, 2004, 2005) sobre a puerícia, suas experiências e o conhecimento que produzem, deixam claro que, para eles, não se trata de comensurar o que a criança aprendeu ou não, o que internalizou ou não sobre determinado assunto, mas, sobretudo, substancial é reconhecer que a criança, a partir do processo de reprodução interpretativa decorrente das interações e experiências vividas em sua cultura de pares ou na cultura do mundo adulto, produz um conhecimento específico, particular e que tem um sentido díspar daquele do adulto.

Eis uma das razões para acreditar que, ao viver suas experiências nos espaços-tempos da escola, a criança com TEA adquire um saber próprio a partir dessa vivência, significa e dá um sentido - sentimentos de preferências e abnegações - singular ao que lhe decorre, que repercute nas relações interativas que estabelece tanto com seus pares quanto com adultos, permitindo apropriar-se da sua própria vida. O olhar que os autores (Corsaro, 2011; Sarmento, 2004, 2005) dispensam à infância, às crianças e à qualidade das experiências vividas nas diferentes dimensões espaçotemporais e culturais corrobora a reflexão a respeito do direito que a criança, com ou sem deficiência, tem de experienciar na escola a completude de sua infância, produzir saberes e, assim, apreender o mundo à sua volta.

\section{METODOLOGIA}

Este artigo traz os resultados parciais de uma investigação desenvolvida no curso de mestrado, e o campo empírico que subsidiou este texto foi instituído utilizando ferramentas do método etnográfico, a partir da observação participante realizada em uma escola pública, tendo como sujeito de investigação uma criança 
com TEA, com seis anos de idade, matriculada na educação infantil, nomeada como Joaquim. No total, realizamos 39 sessões de observação, nos meses de setembro a dezembro do ano de 2018, 3 vezes por semana, durante 3 horas por dia, tempo em que Joaquim permanecia na escola.

Ressaltamos que a opção pelo lócus da pesquisa, intitulada escola "Belém”, deu-se em função de ser um espaço de referência no município, pela sua infraestrutura e atendimento a crianças com TEA, o que corrobora para potencializar a análise das experiências em distintos espaços oferecidos pela escola, tais como: sala de aula, quadra de esportes, biblioteca, sala de informática, refeitório, pátio, além de espaços de recreação ao ar livre, oportunos para investigá-las e obter um panorama rico de informações sobre as experiências e as relações que estabelecem nesses espaços-tempos ${ }^{1}$.

Adotamos como referência o termo espaço-tempo em razão da relevância dessa configuração para o processo de inclusão educacional e do reconhecimento de que o espaço circunscreve parte de um contexto em que Joaquim - nome fictício atribuído ao sujeito da pesquisa - vivencia diversas experiências com tempos aprazados, ou seja, espaço e tempo são concebidos, em conjunto, como uma unidade, como se as crianças compusessem, em tempos análogos, cada experiência. Giaconi e Rodrigues (2014), em estudo acerca da organização do espaço e do tempo na inclusão de sujeitos com autismo, realçam a necessidade de planejamento e estruturação do espaço e do tempo nos contextos escolares, atendendo ao cuidado que se deve ter com as funções biopsíquicas e operativas da pessoa com TEA como: "As coordenações perceptivas (desordens espaço-temporais) [...] e a adaptação (distúrbios de adaptação a pessoas e ambientes)" (Giaconi e Rodrigues, 2014, p. 693).

Quanto à escolha por Joaquim, representa a criança público-alvo da educação especial, matriculada na educação infantil, no turno vespertino, que coincidia com a disponibilidade para efetivação da coleta de dados, visto que definimos como critérios para a seleção do sujeito que a criança tivesse matrícula na educação infantil; que estivesse na educação infantil há mais de um ano na mesma escola; e que fosse dada a anuência dos pais/responsáveis para a realização da pesquisa. Havia, inicialmente, duas crianças que atendiam aos critérios e estavam matriculadas no turno da tarde, entretanto, até a imersão no lócus para a pesquisa de campo, a outra criança pediu transferência da escola.

Em conversa para apresentação da pesquisa e assinatura do Termo de Consentimento Livre e Esclarecido (TCLE), a mãe disponibilizou informações

1 Conquanto a escola apresente uma infraestrutura com diversificados espaçostempos, cada ambiente tinha seu tempo prescrito e sua destinação. Dessa maneira, a turma de Joaquim frequentava em determinados dias da semana, com horários certos, cada espaço escolar, por exemplo: as quartas eram destinadas às aulas de informática, das quais nem sempre ele participava em tempo integral; as quintas eram direcionadas à biblioteca para atividades de leitura, das quais participava com seus pares; a quadra também detinha um dia específico, às quartas-feiras, bem como o parquinho, reservado sempre ao último horário da aula. 
sobre Joaquim que nos foram fundamentais para caracterizar o sujeito da pesquisa. Relatou que aos 3 anos Joaquim foi diagnosticado com CID-11 código 6A02 TEA. A partir de então, começou a frequentar uma instituição especializada, com o objetivo de realizar estimulação precoce. Joaquim frequenta a escola especializada no turno da manhã, a escola regular de educação infantil no turno da tarde e tem uma estagiária que o acompanha nas atividades diárias. Segundo a mãe, Joaquim não apresenta déficit cognitivo e tem pouca dificuldade na comunicação, apesar de ter características atípicas, como a repetição conhecida como ecolalia (ato de repetir as palavras ou frases após serem ouvidas). Seu comprometimento mais acentuado está nas interações sociais, além dos interesses obsessivos e restritos, bem como os comportamentos repetitivos.

O transtorno é caracterizado pelo desenvolvimento atípico em duas dimensões: a comunicação social e os comportamentos, também por apresentar repertório restrito de atividades e interesses, variando de intensidade em cada indivíduo (Schmidt, 2017; Varela e Machado, 2016). A criança com TEA pode apresentar ainda alterações dos sentidos que configuram sua percepção sensorial sobre as coisas, a saber: audição, olfato, tato, visão e paladar.

Para delinear o registro da observação, elaboramos, a priori, um roteiro orientador que continha os seguintes aspectos:

- espaço observado;

- organização espaçotemporal;

- atividade observada;

- relações interativas (como se relaciona com as pessoas e/ou objetos no ambiente da observação? Como se dá a relação com os adultos e com seus pares? Quem tem a iniciativa? Como é a reação da criança? Expressões gestuais e físicas: o que diz nas conversas estabelecidas);

- os sujeitos envoltos nas relações interativas (quem está no ambiente? Com quais pessoas a criança interage: crianças ou adultos?);

- organização social (onde a criança está posicionada, suas idas e vindas nos espaços).

Para tratamento e análise dos dados, empregamos a técnica da análise do conteúdo, que permite a construção de um sistema de categorias, com base nos estudos de Bardin (2011) e Franco (2005). Por meio dessa técnica é possível reorganizar os dados, subsumindo trechos do material, de modo que o texto seja estruturado em unidades, para então ser categorizado e analisado. A técnica é composta por três fases: a pré-análise, constituída pela organização dos documentos submetidos à análise; a exploração do material que trata da codificação, classificação e categorização; e, por fim, o tratamento dos resultados, em que são feitas as inferências e a interpretação dos conceitos (Bardin, 2011). Assim, a técnica possibilitou, por meio de procedimentos objetivos e sistemáticos de descrição dos conteúdos, a obtenção de indicadores e unidades temáticas que coadjuvaram para a elaboração das inferências que realizamos neste texto.

Após profusas leituras no material coletado, analisamos os registros das sessões de observação e iniciamos a construção dos pré-indicadores e indicadores, 
conforme orientam Bardin (2011) e Franco (2005). Na primeira etapa da análise, 29 pré-indicadores que indicassem as experiências vivenciadas por ele na escola emergiram da leitura dos dados qualificados a partir de sua reiteração, da importância salientada na fala ou pelo vestígio emocional presente no comportamento dele. Os dados com vestígio emocional se tornaram perceptíveis tanto pela entonação da fala, às vezes mais excêntrica, quanto por meio de um olhar sui generis, ou ainda mais tangível, quando batia em seu próprio peito em sinal de repulsa ao que lhe acontecia em determinado espaço-tempo escolar.

Em seguida, os pré-indicadores foram aglutinados para compor os indicadores por sua equivalência, complementaridade, ou pela incongruência, cujo objetivo era reduzir a pluralidade. Como resultado, conseguimos agrupar os pré-indicadores em 13 indicadores que evidenciavam as preferências, as abnegações, as relações afetivas e as rotinas instituídas pela escola e as desconstruídas por Joaquim.

A partir dos indicadores, reexaminamos os dados, organizando e correlacionando as informações obtidas com a unidade de contexto da pesquisa, a fim de evidenciar quais experiências a criança vive nos espaços-tempos tão diversificados da escola regular, convivendo com seus pares e com adultos, e compusemos as unidades temáticas e suas categorias de análise, expostas no Quadro 1.

Quadro 1-Categorias de análise por eixo temático.

\begin{tabular}{|l|l|}
\hline Unidades temáticas & \multicolumn{1}{|c|}{ Categorias de análise } \\
\hline \multirow{2}{*}{ Espaços-tempos experienciados } & Espaços-tempos preferidos versus preteridos \\
\cline { 2 - 2 } & Espaços-tempos proibidos para ele versus para as demais crianças \\
\hline $\begin{array}{l}\text { Relações afetivas nos espaços- } \\
\text { tempos escolares }\end{array}$ & Relações afetivas diferentes na cultura com pares \\
\cline { 2 - 2 } & Relações afetivas diferentes na cultura com adultos \\
\hline $\begin{array}{l}\text { Rotinas instituídas nos espaços- } \\
\text { tempos da escola }\end{array}$ & Regras da escola \\
\cline { 2 - 2 } & Desconstrução dos tempos escolares \\
\hline
\end{tabular}

Esta pesquisa foi encaminhada ao Comitê de Ética em Pesquisa da Universidade Federal do Pará-UFPA, para análise sob o CAAE: 00395218.6.0000.0018, e recebeu o parecer no 3.088.217, em 17 de dezembro de 2018.

\section{RESULTADOS E DISCUSSÃO: AS EXPERIÊNCIAS DA CRIANÇA COM TEA NA ESCOLA}

\section{ESPAÇOS-TEMPOS EXPERIENCIADOS}

Nesta primeira unidade temática foram agrupadas as seguintes categorias: "espaços-tempos preferidos versus preteridos" e "espaços-tempos proibidos para ele versus para as demais crianças".

$\mathrm{Na}$ categoria "espaços-tempos preferidos versus preteridos", emergiram aspectos a partir das expressões de Joaquim que externaram a maneira como certos 
espaços na escola são prazerosos em desfavor de outros menos interessantes, com tempos tão inteiriçados pela comunidade escolar e prescritos para cada ambiente. $\mathrm{Na}$ escola de Joaquim, cada espaço tinha um tempo certo que era destinado às crianças da educação infantil, não sendo facultado a ele frequentar certos ambientes em outro momento ou, ainda, permanecer mais tempo em determinado espaço da escola.

Consoante à literatura referente ao TEA, o distúrbio afeta a comunicação, a interação social, a adaptação da criança e a capacidade de aprendizado (Giaconi e Rodrigues, 2014; Varela e Machado, 2016; Schmidt et al., 2016). No caso de Joaquim, ele desenvolveu bastante a comunicação e o aprendizado, possivelmente, por também frequentar, desde a descoberta do transtorno, uma instituição especializada, além da escola regular. Constatamos que, das sintomatologias correlacionadas ao TEA, Joaquim tem um comprometimento mais acentuado com interações sociais, interesses obsessivos e comportamentos repetitivos, perceptíveis nos momentos em que se retirava dos espaços com movimentos recursivos com os braços ou reproduzindo palavras a determinados sujeitos da escola com as mãos nos ouvidos, consequência, talvez, do aspecto sensorial.

No decurso do ir e vir dentro dos espaços-tempos escolares, ele vai optando por preferências a uns em detrimento de outros espaços, menos pela sua condição enquanto criança com TEA e mais pelas circunstâncias envolvidas nessas experiências em cada cenário escolar, como, por exemplo: regras (in)flexíveis para o desenvolvimento de atividades, tempos (in)determinados; relações afetivas (in) expressivas com os sujeitos envoltos que resultavam em sensações de bem-estar, ou não, em alguns espaços, sustendo uma relação eloquente nos ambientes nos quais seus interesses eram mais respeitados.

Quando havia convergência dos espaços-tempos experienciados, com interações propositivas e respeitosas quanto às suas premências enquanto criança com TEA, como o respeito à sua maneira de ser e estar naquele ambiente educativo, transpareciam sentidos afáveis e prazerosos ao que vivia. Entretanto, as experiências em determinados espaços-tempos com regras inflexíveis para o desenvolvimento das atividades com tempos determinados revelaram que os sentidos que ele dava a essas vivências estavam diretamente relacionadas ao que lhe ocorria nesses espaços-tempos. E tal situação nos leva a refletir que a organização espaçotemporal da instituição que se propõe inclusiva precisa ser discutida e pensada pelos sujeitos da escola de maneira a torná-la cada vez mais incitadora, flexível e acessível para as crianças com TEA.

Quando a professora da sala de aula anunciava os momentos e a rotina diária, ele imediatamente reagia com um gesto de satisfação quando se referia a esses espaços, inclusive era o primeiro da fila, demonstrando certa ansiedade. $\mathrm{Na}$ biblioteca, a despeito de não participar das atividades com as crianças transitava livremente pelas prateleiras com anuência da professora, que ora ou outra o tratava com brandura - Joaquim expressava alegria em ir para aquele espaço-tempo, conforme trechos extraídos das notas de campo abaixo. Foi possível perceber igualmente certa ansiedade para saber a hora do parquinho, tanto que, por diversas vezes, perguntava à professora se já iam para aquele espaço. 
Quando a professora pediu para formarem fila para irem para a biblioteca, ele saiu na frente dos colegas para ser o primeiro da fila. Lá tinham 2 (duas) professoras, ele entrou, mas não sentou com as outras crianças para ouvir a história, ficou andando entre os armários onde ficam os livros e a estagiária atrás dele pedindo para ele sentar. Depois, ao ouvir a música, ele sentou no chão e ficou junto às crianças. (observação participante, 24 out. 2018)

A sala de aula sobressaiu como um dos espaços-tempos pertencentes a essa categoria. Quanto à rotina da sala de aula regular, destacamos os tempos diariamente demarcados para as atividades, como a hora da chamada, da brincadeira na roda, da atividade em grupo e individual e do brinquedo, bem como um espaço-tempo instituído especificamente para ele: o tapete com seus brinquedos pessoais. As crianças têm autonomia dentro de sala de aula, brincam umas com as outras e circulam com certa liberdade. As carteiras ficam dispostas em mesas quadradas, com quatro a três crianças em cada mesa e elas podem se ver e conversar entre si. A sala tem um cantinho de leitura, dois armários para colocar os brinquedos e os recursos pedagógicos que são de uso coletivo.

Ficou cognoscível que, quando a atividade envolvia algo do domínio dele, sentia-se muito à vontade e gostava de estar na sala de aula. Um dos tempos que o atraíam na sala de aula era a rodinha, tanto a destinada para contação de histórias quanto a para a brincadeira da lata, em que, ao sortear uma letra, a criança deveria proferir qual era e indicar uma palavra que iniciava pela letra sorteada, conforme fragmento abaixo das notas de campo: "- Corre, tia, corre! Vai começar a brincadeira da lata, eu vou acertar todas, eu sempre acerto todas as letras, você sabia?" (observação participante, 26 set. 2018).

Outrossim, o interesse pelo espaço-tempo da sala de aula regular se revelou em outros momentos, como aqueles em que, para esgueirar-se dos espaços em que não se sentia bem, quiçá por conta dos aspectos sensoriais, retornava imediatamente para a sala de aula e ficava à espera dos seus pares. Ali existia seu tapete para os momentos dos brinquedos, o quadro para escrever e desenhar enquanto esperava o retorno dos amigos. Ressaltamos o papel da professora de Joaquim, que cooperava em muito para que aquele ambiente fosse tão prazeroso, visto que, a cada tempo na sala de aula, era respeitado em suas singularidades, tanto para a realização de suas atividades, que nem sempre coincidiam com o tempo das demais crianças, quanto para a sua forma de participação, de acordo com excertos das notas de campo expostas a seguir: "Da biblioteca foram em fila para o refeitório, ele correu na frente, como nos demais dias, olhou o lanche e falou para a estagiária que queria ir para a sala de aula com a professora, e por lá ficou ora desenhando no quadro branco, ora fazendo as atividades do dia” (observação participante, 25 set. 2018); "Como nos demais dias, quando deu a hora do intervalo, ele foi no refeitório, mas quando viu todos lá, pegou a minha mão e quis voltar para a sala. Nesse momento a estagiária foi lanchar. Ele pediu para ficar na sala durante todo o intervalo" (observação participante, 2 out. 2018).

Com efeito, diante da preocupação em respeitar as especificidades dele, a docente procurava continuamente (re)inventar os tempos escolares, tanto da 
escola enquanto instituição que, em sua estrutura intrínseca, está regulada por regras de convivência quanto do tempo da sala de aula, especialmente dada a complexidade dos tempos escolares, caracterizados por suas várias temporalidades. Realidade perceptível nos momentos em que ele se ausentava da sala de aula - ia ao banheiro, ao refeitório, bebedouro acompanhado pela estagiária, pois eram respeitados pela docente e significavam, para ela, interrupções temporais importantes para o desenvolvimento da criança e para o processo de escolarização à medida que, quando regressava à sala, envolvia-se e participava das atividades. Acrescente-se ainda que a professora continuadamente flexibilizava o tempo de suas atividades, nem sempre coincidente ao tempo das demais crianças, bem como quando ampliava o tempo de uma atividade que despertava o interesse de Joaquim.

Da mesma forma acontecia com os indicadores dos espaços-tempos preteridos, visto que anunciava seu descontentamento nos locais que não oportunizavam razoável liberdade de escolha para realização das atividades, a exemplo da sala de informática. Habitualmente, nesse espaço-tempo, a atividade direcionada à educação infantil consistia na apresentação de vídeos educativos que nem sempre despertavam o interesse de Joaquim, conforme trecho abaixo extraído das notas de campo, quando perguntamos por que não participava da aula e ele respondia: "- Porque nunca posso ligar o computador, nunca, só ficar sentado. Eu tô cansado disso!” (observação participante, 2 out. 2018).

Outro momento dificultoso era quando as crianças saíam para o refeitório, pois ele voltava imediatamente para a sala. Sua rotina era sempre a mesma, retornava para sala e lanchava sem a companhia dos seus pares. Ao perguntarmos por que ele não ficava com as outras crianças no pátio, ele pronunciava com as mãos nos ouvidos: "- Porque eles gritam muito, todo mundo lá fora grita muito! Eu nunca consigo comer!” (observação participante, 9 out. 2018).

Dessa maneira, quando há confluência entre os espaços, os sujeitos e os interesses dele em certos ambientes da escola, ele dá sentido aprazível às suas experiências e consegue externar suas emoções aos sujeitos envolvidos no processo educativo, evidenciando sua (in)satisfação com o que lhe advém, categorizando espaços de preferência ou rejeição.

$\mathrm{Na}$ categoria "espaços-tempos proibidos para ele versus para as demais crianças", os dados apontaram que ele conseguia discernir espaços de livre acesso para ele em condições desiguais, quando equiparado às outras crianças, e exteriorizava essa realidade no ambiente educativo, como, por exemplo, nos episódios em que quis brincar de "amarelinha" ou ir para a quadra, pois, como não era permitido deixá-lo ir sozinho - brincar livremente e em horários diferentes aos definidos -, ele se mostrava irritadiço com o funcionário que não permitia seu acesso a esses ambientes, visto que só liberava o portão após a companhia da professora ou da estagiária, como no relato abaixo.

Quando o vimos voltando de braços cruzados e aborrecido, perguntamos o que havia acontecido. Ele respondeu:"-Esse homem é muito chato e malvado, ele só deixa as outras crianças "sair", ele deixa todo mudo sair menos eu. Que droga! Vou mandar me avô bater nele” (observação participante, 16 out. 2018). 
E continuamos: “- mas ele gosta de você, se preocupa com você!”. Quando respondeu: “- Não gosta não! Só gosta dos outros, de mim não, porque é muito malvado. Vou mandar meu avô bater nele. Ele vai apanhar do meu avô" (observação participante, 16 out. 2018).

Pereira (2011), em pesquisa de mestrado no tocante ao que dizem as crianças do entrelugar entre o centro de atendimento educacional especializado e a escola de educação infantil, conclui que é necessário "ressignificar concepções sociais tão impregnadas em nossa sociedade, que precisam ser repensadas em busca de vivermos em uma sociedade que valorize as diferenças e a alteridade de cada sujeito" (Pereira, 2011, p. 139), em vez de privilegiar as limitações impostas pela condição singular de cada criança.

Santos $(2015$, p. 236), ao enunciar que experiência pueril "envolve os sentidos pela via de um corpo sensível, em que aquilo que toca a criança, de certo modo, a modifica", coadjuva a compreender que fatores como o contexto ou as relações que estabelece com seus pares, com adultos e com objetos, têm um sentido único às suas vivências nos espaços-tempos educativos. Dessa forma, a experiência que Joaquim vivencia origina novos saberes e culturas próprias que diferem da cultura do mundo adulto.

Do mesmo modo que as demais crianças, Joaquim consegue discernir claramente o sentido ou sem sentido ${ }^{2}$ do que lhe sucede em determinados espaços-tempos a partir das relações que constrói com seus pares e com os adultos, das atividades preferidas e preteridas por ele, que o fazem desaceitar alguns ambientes e aceitar melhor outros.

Destarte, quando se sentia atendido em suas necessidades e respeitado em suas maneiras de ser e estar em certos espaços-tempos escolares, em que flexibilizações eram permitidas, tais episódios coadjuvavam para que ele participasse das atividades educativas, como nos ambientes da biblioteca, onde podia participar da atividade no seu tempo, ou quando lhe permitiam ficar em outros ambientes, como a quadra, em tempos não prescritos pelas regras, ou, ainda, quando realizava as atividades da rotina da sala de aula regular em outro tempo.

\section{RELAÇÕES AFETIVAS NOS ESPAÇOS-TEMPOS ESCOLARES}

Desta segunda unidade temática originaram as categorias: "relações afetivas diferentes na cultura com pares" e "relações afetivas diferentes na cultura com adultos".

$\mathrm{Na}$ categoria "relações afetivas diferentes na cultura com pares", a análise dos dados propiciou identificar a maneira como significa suas experiências ao manifestar dissemelhantes formas para se relacionar com seus congêneres. Quando as crianças eram da sua turma, mantinha uma relação mais próxima de familiaridade com elas, ainda que, às vezes, os tratasse de forma inflexível e incomplacente quando os amigos lhe dirigiam a palavra ou apenas se sentavam ao seu lado, mas sustinha interação com as crianças que se mostravam tole-

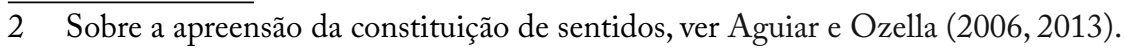


rantes, pacientes e zelosas, ora cedendo o brinquedo, ora dando a vez para ele nas atividades e brincadeiras, entre outras atitudes pacíficas. E, embora o foco desta pesquisa não fosse dar a voz a outros sujeitos que não Joaquim, quando ocorriam essas situações na sala de aula regular, diziam: "- Ele é assim mesmo, tia, 'brabo'! Não mexe com ele, é o jeito dele, ele é assim mesmo!” (observação participante, 11 out. 2018).

Externavam tanto com atitudes quanto com suas falas terem o discernimento quanto ao jeito de ser de Joaquim ou, ainda, a compreensão da deficiência como uma condição dele. Não demonstraram vê-lo como uma criança doente, talvez reflexo de um trabalho de aceitação relevante realizado pela professora da classe regular ou, no caso específico de Joaquim, da ausência de uma condição física diferente. Morais (2014), intentando descobrir o que falam as crianças da educação infantil em pesquisa de mestrado sobre a inclusão escolar, concluiu que as crianças, quando não influídas por prejulgamentos, aceitam o outro diferente, inclusive quando a deficiência é aparente.

Entretanto, quando a atividade escolar se dava de maneira universal, com todos os alunos envolvidos, sublinhamos o fato de ele se manter distante das crianças de outras turmas e de só permanecer no ambiente quando a professora da sala regular o acompanhava. Os dados coletados confirmam essa interação diferente quando com pares de outra sala, conforme trecho de uma das sessões da observação transcrito abaixo: "- Eu gosto muito do parquinho, mas a tia só leva na hora da saída e meu avô vem me buscar sempre nessa hora, droga! Lá a gente brinca só, não tem aqueles meninos chatos, né! [referindo-se às crianças de outras turmas]" (observação participante, 4 dez. 2018).

Joaquim realçou gostar de ir para o parquinho, posto que só a educação infantil frequentava, expressou inclusive a frustração de não poder participar todos os dias, pois o tempo reservado ao parquinho na rotina instituída pela escola era sempre ao final do dia. Contudo, ele, por ter um horário diferenciado, saía uma hora antes e, por vezes, não participava desse momento.

É inequívoca a forma díspar como se relaciona na cultura de pares com as crianças da sua sala e com as demais crianças da escola, dado que se sentia mais confiante quando estava só com os pares da sua sala de aula e, quando na presença de outros, participava parcialmente das atividades propostas nos espaços-tempos da escola. O maior comprometimento dele está nas interações sociais. Portanto, há a imprescindibilidade de a instituição educativa deter um olhar mais atento às relações interativas oportunizadas nas diversas configurações espaço-temporais da escola, a fim de contribuir para um convívio mais harmonioso de Joaquim com os sujeitos escolares, visto que a complexidade de suas características de ser e estar no mundo influi diretamente no seu desenvolvimento.

Os dados confluem com o que Schmidt et al. (2016) adverte, em seus estudos, no que diz respeito à importância, para as crianças com TEA, da interação entre pares, sendo um fator ainda pouco explorado nas pesquisas e entre os sujeitos da escola. O diálogo entre os símeis é uma das questões a considerar em contextos educacionais inclusivos, bem como com os adultos circundados na conjuntura da escola. Em especial a criança com TEA, que tem no seu desen- 
volvimento comprometimento acentuadamente atípico na interação social, essa é uma das razões para que o contexto escolar coadjuve para que haja interação cada vez maior entre os pares e com os adultos.

Sobre isso, sublinhamos o que exprimem Camargo e Bosa (2009, p. 66):

A interação com outras crianças da mesma faixa etária proporciona contextos sociais que permitem vivenciar experiências que dão origem à troca de ideias, de papéis e o compartilhamento de atividades que exigem negociação interpessoal e discussão para a resolução de conflitos. No grupo de pares emergem as regras que estruturam as atividades de cooperação e competição.

A despeito do que afirmam alguns autores (Carmargo e Bosa, 2009; Schmidt et al.,2016) sobre o fato de que a oportunidade de conviver com seus pares faculta à criança com TEA o incitamento às suas competências interativas, não se deve esquecer de que esse processo de convivência compartilhada, por via da inclusão na escola comum, demanda atenção às idiossincrasias de cada criança e envolvimento de todos os sujeitos do mundo adulto implicados no contexto inclusivo, como técnicos, docentes, funcionários e a comunidade escolar.

Dessarte, observamos que esse convívio mais propínquo de Joaquim com os pares de sua sala independe da condição dele enquanto criança com TEA. Zaikievicz (2017), em pesquisa de mestrado sobre o que dizem as crianças da pré-escola com relação à instituição educativa, igualmente revelou que o comportamento e as preferências das crianças estão relacionados àqueles amigos com quem têm mais intimidade ou proximidade; logo, propendem a comparticipar brincadeiras, na maioria das vezes, com as mesmas crianças.

$\mathrm{Na}$ categoria "relações afetivas diferentes na cultura com adultos", exteriorizou, igualmente, distintas experiências. No tocante à interação, sua relação com os adultos revelou a predileção por aqueles que se mostravam mais solícitos às pretensões dele, dialogavam com ele rotineiramente, permitiam expressar suas ideias e seus sentimentos e, de forma antagônica, sucederam momentos apreensivos e conflituosos com alguns agentes da escola. Outro fato axiomático que indicou essa diferença na interação com adultos diz respeito à maneira como expressava certo carinho com as professoras da sua sala, mantendo uma relação mais harmoniosa; todavia, manifestava emoções de afetividade marcadas pela recusa quanto a outros sujeitos do contexto escolar.

Não obstante ao fato de o transtorno não ter uma configuração única de manifestação, "mas uma variação de sinais desde traços bem leves [...], até um quadro complexo [...], lembrando que não é uma constante o aparecimento de todas as dificuldades ao mesmo tempo, porém a dificuldade de interação social aparece em todos, em graus variados" (Gonçalves, 2015, p. 48), e considerando essas características próprias da criança com TEA no que tange à capacidade de assentar relações sociais ou afetivas, ele demonstrava irritabilidade quando se dirigia a alguns sujeitos da escola, acompanhada de gritos em certas experiências vividas, ou andava de um lado a outro com movimentos nos braços e mãos, além da repetição persistente de palavras ou outras ações que findavam em uma 
ausência de interação social. Em outras palavras, uma interação inadequada com esses sujeitos escolares.

Isso se evidencia nos registros em uma das sessões da observação, quando machucou uma outra criança no pátio, na hora do intervalo, e foi levado por um funcionário para a administração. Quando ele saiu da sala, perguntamos o que havia ocorrido, ao que nos respondeu: "- Eu não tive culpa. Eu não gosto dessa mulher! Sempre ela que briga comigo! Porque tudo sou eu, tudo sou eu nesse diabo! Eu vou pedir uma folga, uma folga, eu preciso de uma folga dessa escola" (observação participante, 12 nov. 2018).

Observamos que os vislumbres em relação a Joaquim sinalizam indícios daquele contexto educativo e revelam as expectações dirigidas a ele, ao prejulgarem suas condutas e atitudes. Plaisance (2005), ao proferir com relação ao papel que a criança com deficiência representa - a ponto de a deficiência ser preponderante diante das peculiaridades inerentes à infância e à criança -, nos ajuda a compreender como as significações a respeito de Joaquim e as atitudes dos sujeitos escolares com ele espelham reflexos em suas manifestações ao que lhe transcorre nos espaços-tempos do ambiente educativo.

Apropriando-nos de Pereira (2011), nota-se que a peculiaridade do modo de ser e estar da criança com TEA na infância acaba sendo declinado em detrimento da deficiência e faz com que ela aufira estereótipos de diversas categorias, que desvalorizam sua potencialidade, sua capacidade de criar hipóteses, sendo vista como uma criança ora inábil, ora desinteressada, por não realizar algumas atividades delineadas em tempos similares para as demais crianças, desconsiderando suas especificidades. Ouvi-la e respeitá-la em sua maneira de ser possibilita aos adultos conhecer suas realidades, tornando-se possível planejar um cotidiano institucional que venha ao encontro de seus interesses (Zaikievicz, 2017).

Isso posto, naquele contexto espaçotemporal, é possível inferir, por meio das exteriorizações de Joaquim no tocante às suas experiências vivenciadas, conceitos com relação à criança com TEA com profundas significações representadas em condições de incompletude ou inépcia, perceptível em conjunturas nas quais era visto como um vir a ser, ou seja, criança incapaz, como nos episódios em que ele não podia transitar sozinho pelos ambientes intra/extra sala de aula. A relação com a cultura do mundo adulto está diametralmente relacionada a como os adultos se comportam diante das iniciativas dele nos ambientes da escola, razão pela qual se faz imperioso ressignificar as concepções dos adultos com referência à infância enquanto classe geracional heterogênea e à criança com TEA para a existência de um contexto mais inclusivo.

\section{ROTINAS INSTITUÍDAS NOS ESPAÇOS-TEMPOS DA ESCOLA}

A terceira unidade temática produziu as categorias: "regras da escola" e "desconstrução dos tempos escolares".

$\mathrm{Na}$ categoria "regras da escola", despontaram aspectos como comportamentos e reações de agitação, ansiedade e impulsividade que, ocasionalmente, eram estigmatizados pelos agentes da escola como agressividade, mas que, por 
trás, expressavam tanto reações às características do aspecto sensorial quanto respostas de Joaquim a uma configuração espaçotemporal da escola com regras instituídas que findavam em uma organização extremamente linear dos tempos da escola; logo, não anuíam qualquer forma de flexibilidade às crianças com TEA, às suas formas de ser e estar no mundo e às peculiaridades da infância, conforme fragmentos extraídos das notas de campo:

$\mathrm{Na}$ hora da atividade na sala de informática, ele não entrou na sala e tentou acessar o espaço que dá acesso ao jogo da amarelinha que fica bem ao lado, mas não conseguiu pois só é permitido seu acesso ao local no horário do recreio e acompanhado. Logo em seguida, tentou ir para a quadra, sem sucesso, pois o funcionário estava no portão e não permitiu seu acesso ao espaço da quadra naquele momento. Quando disse: “- Você viu né, tia? Eu nunca posso ir pra lá! Ele nunca deixa!" [referindo-se ao funcionário]. (observação participante, 2 out. 2018)

Durante o momento da brincadeira, ele não parou sentado na cadeira, andou entre as mesas, pegava brinquedos das mãos dos colegas, a estagiária o acompanhava em todas as mesas. $\mathrm{Na}$ hora do intervalo, a professora pediu para formarem a fila, ele saiu antes dos colegas, mas não quis lanchar e voltou para sala. Nesse dia, pela primeira vez, a professora não o deixou ficar na sala de aula regular no momento do intervalo. Ele se mostrou bastante irritado com a situação de ter que ficar no pátio. Embora significasse um espaço para correr e brincar livremente, para ele apresentava um sentido de algo doloroso ter que ficar com aqueles sujeitos escolares. Joaquim pegou o lanche que trouxe de casa, comeu e logo em seguida ficou gesticulando enquanto andava de um lado para o outro no pátio com as mãos no ouvido: “- Eu não gosto de ficar aqui! Eu não gosto, porque eu sempre tenho que ficar nessa droga de pátio”. (observação participante, 19 nov. 2018)

As reações de Joaquim de sensibilidade ao som integram uma das manifestações da criança com TEA e, apesar de o refeitório e o pátio significarem espaços livres para brincar, para ele tinham outro sentido, visto que ele imediatamente voltava para a sala de aula e só se dirigia ao pátio da escola quando as crianças não estavam mais lá, ou seja, criava um tempo diferente, só seu, para esses ambientes da escola. E, quando era compelido a permanecer nesses espaços-tempos, mostrava-se ansioso, pois não queria ficar naqueles tempos estabelecidos e, por vezes, bastante irritadiço com a situação, andava de um lado para o outro com movimentos repetitivos com as mãos.

Os dados levantados no estudo expressam uma forma escolar com tempos inflexíveis e predeterminados, como se fossem únicos e análogos a cada criança em seu processo de ensino-aprendizagem, um tempo comum a toda criança, independentemente de suas necessidades para viver as experiências na escola. Evidenciamos, nas manifestações de Joaquim, o quão urgente é 
refletir sobre as possibilidades, oportunidades e flexibilizações dos tempos e das regras sobre os espaços, a fim de suprir e atender às premências das crianças com ou sem deficiência.

A respeito de oportunizar vivenciar suas experiências respeitando seus tempos em cada espaço escolar, Santos (2015, p. 235) atenta que a experiência infantil "é sutil, pois o que a criança apreende o faz de corpo inteiro; de acordo com seus sentimentos, seus interesses, suas necessidades, nem sempre dominadas e controladas pelos adultos". Delmondes e Silva (2018, p. 88) aditam, asseverando que "a criança é um sujeito que passa pela experiência e que a experiência passa por ela. Não se pode predizer sobre a experiência, assim como não se podem prever os tempos, ritmos, aprendizados de uma criança”, à medida que a pluralidade das experiências se passa em cada infante de forma díspar.

Com efeito, Joaquim demonstrou em inúmeros momentos a vontade de ir e vir, permanecer mais tempo, ou não, nas extensões da escola, a exemplo dos momentos em que queria brincar de amarelinha ou na quadra em tempo contrário ao estipulado para seus pares. Assim como nos dias em que preferia realizar todas as atividades escolares em um único tempo, ou ainda quando queria que determinada atividade se perpetuasse por mais tempo, como a atividade pedagógica da lata.

Na categoria "desconstrução dos tempos escolares", os dados expressam a resposta de Joaquim diante de regras rígidas instituídas pela escola, na qual busca desconstruir alguns tempos enrijecidos, com horários preestabelecidos e dias estipulados para o desenvolvimento de certas atividades, a fim de ajustar seus interesses e minúcias em cada ambiente em que vive suas experiências, conforme descrições abaixo constantes nos registro de campo.

$\mathrm{Na}$ volta do intervalo, quando a professora distribuiu as atividades às demais crianças ele ficou andando entre as mesas e cadeiras, indo e vindo pelo corredor da escola, gesticulando com as mãos nos ouvidos como se o barulho estivesse the incomodando e não parou para fazer a atividade do dia que era sobre partes do corpo humano enquanto as outras crianças faziam a atividade. Ela o deixou livre para fazer em outro tempo. Ele fez a atividade durante o intervalo do recreio quando seus pares estavam no pátio da escola. (observação participante, 26 set. 2018).

Hoje a professora antecipou a atividade livre na quadra e ele saiu correndo mas foi primeiro na amarelinha, pediu para eu brincar com ele uma vez, e só muito tempo depois foi para a quadra participar da atividade do circuito (a professora fez com barbante várias formas geométricas e distribuiu os alunos em grupos e falava qual era a forma para ficar). (observação participante, 16 out. 2018).

Com momentos definidos para a realização de certas atividades em razão da sua configuração espaçotemporal, a escola demarca o uso dos espaços de tal 
forma, que o leva a constantes desestruturações e (re)construções das regras em determinados ambientes e nos dá indícios para pensar sobre como a instituição educativa pode corroborar para atendê-lo em suas especificidades, de maneira a permiti-lo viver suas experiências.

Giaconi e Rodrigues (2014), ao abordar acerca da organização espaçotemporal na inclusão de sujeitos com TEA, explicitam que "o tempo é mais difícil de ser representado e de ser compreendido, por suas características de abstração e fugacidade que, com frequência, conduzem o sujeito autista a perder-se no tempo" (Giaconi e Rodrigues, 2014, p. 696), e cooperam para entender como Joaquim, a todo momento, lida com a organização espaçotemporal da escola "Belém" em sua incessante busca pela desconstrução desses tempos escolares que nem sempre atendem às suas singularidades.

$\mathrm{E}$, consoante às autoras, é comum que esses comportamentos levem a uma compreensão pela comunidade escolar como "condutas de recusa e rejeição"; logo, o "planejamento de linhas-guia para a inclusão escolar de sujeitos com autismo não pode excluir uma intencional atenção à estruturação dos espaços e dos tempos" (Giaconi e Rodrigues, 2014, p. 697). Ou seja, faz-se imperioso "atentar à predisposição de ambientes e tempos escolares, à luz dos problemas de suas necessidades especiais de previsibilidade, de orientação imediata, estabilidade, fácil compreensão da situação e da passagem do tempo" (Giaconi e Rodrigues, 2014, p. 700), a ponto de propiciar à criança com TEA uma condição favorável quanto aos espaços-tempos que a permita vivenciar experiências subjetivas no contexto da inclusão.

Durante a coleta de dados, em raras exceções e em certos espaços, foi-lhe oportunizado viver experiências em tempos descoincidentes às regras da escola, externando, mais uma vez, que a relação que ele mantém com a cultura adulta da escola se dá de maneira dissemelhante, pois os sujeitos de alguns espaços-tempos flexibilizavam as regras para atender a seus anseios e suas pretensões.

$\mathrm{E}$, nesse desenovelar-se às regras instituídas dos espaços-tempos da escola, ele vai significando suas experiências à medida que desconstrói as rotinas instituídas fixas e consegue flexionar os horários rijos dos espaços-tempos, empenhando-se em estabelecer novas relações espaços-temporais, a partir ora das relações afetivas que estabelece com os sujeitos, ora das atividades das quais participa nesses espaços. Congruente ao que afirmam Furlan, Lima e Lima (2019), faz-se necessário, na escola, "relativizar as atividades propostas, diversificá-las, tratá-las com linguagens e metodologias diferenciadas, ser menos rígidos em relação ao tempo, ou seja, pensá-lo na relação entre a 'lógica adulta' e a 'lógica infantil”' (Furlan, Lima e Lima, 2019, p. 95, grifo nosso).

Enfim, atentas à configuração espaçotemporal experienciada por Joaquim na escola "Belém", buscamos captar da melhor forma possível os aspectos que levassem a legitimar o protagonismo dele, desvelando suas impressões e vivências individuais e coletivas ao estabelecer relações com outras lógicas que não as do mundo adulto, com tempos rijos para determinada atividade, bem como a maneira como rompe esses paradigmas e dá sentidos aprazíveis, ou não, ao que vive no espaço educativo no contexto da inclusão. 


\section{CONSIDERAÇÕES FINAIS}

Refletir sobre as experiências de Joaquim nos espaços-tempos diversificados da escola pressupõe reconhecer a criança como sujeito de direitos que vivencia diferentes experimentações, em que devem ser consideradas suas nuances e diferenças, além de reiterar os desafios educacionais no que tange à adequação dos espaços-tempos escolares para a construção de um contexto mais inclusivo e atento às capacidades e às potencialidades da criança com TEA.

Pelo prisma de quem, por certo, vivencia experiências no contexto da inclusão na escola regular, este estudo traz contribuições ao campo da educação especial e às práticas na perspectiva inclusiva destinadas às crianças com deficiência ao desvelar que, mesmo com Joaquim sendo visto por alguns sujeitos escolares apenas pela sua condição atípica do desenvolvimento e que acreditam mais em suas limitações do que em suas capacidades, ele participa da vida escolar, interage com os pares da sua sala de aula e com alguns adultos com reflexos propositivos em seu desenvolvimento.

Nesse sentido, os resultados reafirmam a imprescindibilidade de ampliar estudos que busquem desvelar a voz da criança com deficiência em suas diversificadas formas de expressão acerca das experiências vividas nos espaços-tempos da escola, reconhecendo-a como sujeito que traz singularidades, por vezes, não exclusivas a sua deficiência, mas com peculiaridades próprias da infância que envolvem temporalidades únicas, não possíveis de serem rotuladas e programadas em espaços-tempos escolares tão rígidos.

Longe de encerrar o assunto e tomá-lo como verdade, dada a diversidade de manifestações do transtorno e seus dissemelhantes sintomas e, ao profuso e amplo campo da educação especial, esperamos que as discussões aqui implementadas contribuam com novas reflexões sobre a inclusão na educação infantil, a fim de ampliar a discussão e coadjuvar para a ressignificação das práticas pedagógicas de maneira a garantir intencionalidades educativas na utilização dos espaços-tempos da escola regular.

\section{REFERÊNCIAS}

AGUIAR, W. M. J.; OZELLA, S. Núcleos de significação como instrumento para a apreensão da constituição dos sentidos. Psicologia: Ciência e Profissão, Brasília, v. 26, n. 2, p. 222-245, jun. 2006. Disponível em: https://www.scielo.br/scielo. php?pid=S1414-98932006000200006\&script=sci_abstract\&tlng=pt. Acesso em: 22 out. 2019. https://doi.org/10.1590/S1414-98932006000200006

AGUIAR, W. M. J.; OZELLA, S. Apreensão dos sentidos: aprimorando a proposta dos núcleos de significação. Revista Brasileira de Estudos Pedagógicos, Brasília, v. 94, n. 236, p. 299-322, jan./abr. 2013. Disponível em: https://www.scielo.br/scielo. php?pid=S2176-66812013000100015\&script=sci_abstract\&tlng=pt. Acesso em: 22 out. 2019. https://doi.org/10.1590/S2176-66812013000100015

BARDIN, L. Análise de conteúdo. São Paulo: Edições 70, 2011. 
BENJAMIN, W. Reflexões sobre a criança, o brinquedo, a educação. São Paulo: Duas Cidades 34, 2002.

BONDÍA,J.L. Notas sobre a experiência e o saber de experiência. Revista Brasileira de Educação, Rio de Janeiro, n. 19, p. 20-28, abr. 2002. Disponível em: http://www. scielo.br/scielo.php?script=sci_arttext\&pid=S1413-24782002000100003\&lng=en\&nr $\mathrm{m}=$ iso. Acesso em: 20 out. 2019. https://doi.org/10.1590/S1413-24782002000100003 CAMARGO, S. P. H.; BOSA, C. A. Competência social, inclusão escolar e autismo: revisão crítica da literatura. Psicologia \& Sociedade, São Paulo, v. 21, n. 1, p. 65-74, jan./abr. 2009. Disponível em: https://lume.ufrgs.br/handle/10183/20834. Acesso em: 16 set. 2019. https://doi.org/10.1590/S0102-71822009000100008

CARMO NETO, H. Percepções de educadores quanto à inclusão e integração de crianças e jovens com necessidades especiais. 2000. 94f. Dissertação (Mestrado em Psicologia) - Pontifícia Universidade Católica de São Paulo, São Paulo, 2000.

CORSARO, W. A. Sociologia da infância. Porto Alegre: Artmed, 2011.

DELMONDES, M. O.; SILVA, T. M. Os campos de Experiências na Base Nacional Comum Curricular: do Positivismo às Inversões Cotidianas. Linguagens, Educação e Sociedade, Teresina, ano 23, n. 38, p. 72-98, jan./jul. 2018. Disponível em: https:// revistas.ufpi.br/index.php/lingedusoc/article/view/7693. Acesso em: 22 set. 2019. https://doi.org/10.26694/les.v1i38.7693

FRANCO, M. L. P. B. Análise de conteúdo. 2. ed. Brasília: Líber Livro, 2005.

FURLAN, S. A.; LIMA, J. M.; LIMA, M. C. Culturas infantis: a reiteração e as concepções de tempo na Educação Infantil. Revista Zero-a-Seis, Florianópolis, v. 21, n. 39, p. 81-98, jan.-jun. 2019. Disponível em: https://www.researchgate. net/publication/332055467_Culturas_infantis_a_reiteracao_e_as_concepcoes_ de_tempo_na_Educacao_Infantil. Acesso em: 22 ago. 2019. https://doi. org/10.5007/1980-4512.2019v21n39p81

GIACONI, C.; RODRIGUES, M. B. Organização do espaço e do tempo na inclusão de sujeitos com autismo. Educação \& Realidade, Porto Alegre, v. 39, n. 3, p. 687-705, set. 2014. Disponível em: https://www.scielo.br/scielo.php?pid=S217562362014000300004\&script=sci_abstract\&tlng=pt. Acesso em: 24 set. 2019. https:// doi.org/10.1590/S2175-62362014000300004

GONÇALVES, D. C. C. Proposta de análise das práticas interativas de crianças diagnosticadas com transtorno do espectro autista: uma perspectiva discursiva. 2015. 190f. Tese (Doutorado) - Programa de Pós-Graduação em Letras, Pontifícia Universidade Católica de Minas Gerais, Belo Horizonte, 2015.

HERRERA, M. A. A vida na escola estadual fotografada e narrada por crianças com deficiência. 2016. 186f. Dissertação (Mestrado em Educação) - Programa de Pós-Graduação em Educação, Universidade Cidade de São Paulo, São Paulo, 2016.

MAISATTO, R. O. Corpos e gênero: representações das crianças de uma instituição especializada no atendimento às pessoas com deficiência intelectual e múltipla no município de Corumbá/MS. 2014. 135f. Dissertação (Mestrado em Educação) - Programa de Pós-Graduação em Educação, Universidade Federal de Mato Grosso do Sul, Corumbá, 2014. 
MELO, D. M. O que a família de crianças com deficiência tem a nos dizer sobre a inclusão escolar de seus filhos? 2013. 151f. Dissertação (Mestrado em Educação) Programa de Pós-Graduação em Educação, Universidade Federal do Espírito Santo, Espírito Santo, 2013.

MORAIS, C. R. C. Inclusão escolar: o que falam as crianças da educação infantil. 2014. 102f. Dissertação (Mestrado em Educação) - Programa de Pós-Graduação em Educação, Universidade do Vale do Itajaí, Itajaí, 2014.

PEREIRA, I. C. J. Centro de atendimento educacional especializado e escola de educação infantil: o que dizem as crianças desse entrelugar. 174f. Dissertação (Mestrado em Educação) - Centro em Educação, Universidade Federal do Espírito Santo, Vitória, 2011.

PLAISANCE, E. Denominações da infância: do anormal ao deficiente. Educação \& Sociedade, Campinas, v. 26, n. 91, p. 405-417, ago. 2005. Disponível em: http://www. scielo.br/scielo.php?script=sci_arttext\&pid=S0101-73302005000200006\&lng=en\&nr $\mathrm{m}=$ iso. Acesso em: 23 jul. 2019. https://doi.org/10.1590/S0101-73302005000200006 SANTOS, S. V. S. Walter Benjamin e a experiência infantil: contribuições para a educação infantil. Pro-Posições, v. 26, n. 2, p. 223-239, dez. 2015. Disponível em: https://periodicos.sbu.unicamp.br/ojs/index.php/proposic/article/view/8642407. Acesso em: 20 jun. 2019.

SARMENTO, M. J. As culturas da infância nas encruzilhadas da segunda modernidade. In: SARMENTO, M. J.; CERISARA, A. B. Crianças e miúdos: perspectivas sócio-pedagógicas da infância e educação. Porto: ASA, 2004. p. 9-34.

SARMENTO, M. J. Gerações e alteridade: interrogações a partir da sociologia da infância. Educação \& Sociedade, Campinas, v. 26, n. 91, p. 361-378, maio/ago. 2005. Disponível em: http://www.scielo.br/pdf/es/v26n91/a03v2691.pdf. Acesso em: 2 out. 2019. https://doi.org/10.1590/S0101-73302005000200003

SCHMIDT, C. Transtorno do espectro autista: onde estamos e para onde vamos. Psicologia em Estudo, Maringá, v.22, n. 2, p. 221-230, abr./jun. 2017. Disponível em http://periodicos.uem.br/ojs/index.php/PsicolEstud/article/view/34651/pdf. Acesso em: 25 mar. 2019. https://doi.org/10.4025/psicolestud.v22i2.34651

SCHMIDT, C. et al. Inclusão escolar e autismo: uma análise da percepção docente e práticas pedagógicas. Psicologia: Teoria e Prática, São Paulo, v. 18, n. 1, p. 222-235, abr. 2016. Disponível em: http://pepsic.bvsalud.org/scielo. php?script=sci_abstract\&pid=S1516-36872016000100017\&lng=pt\&nrm=iso. Acesso em: 25 jun. 2019.

TONUS, D. Percepção de pais e professores de crianças e adolescentes com deficiência sobre o término das classes especiais e a inclusão em escolas regulares. 2010. 82f. Dissertação (Mestrado Profissionalizante em Reabilitação e Inclusão Social) - Centro Universitário Metodista IPA - Habilitação e Inclusão, Porto Alegre, 2010. VARELA, B.; MACHADO, P. G. B. Uma breve introdução sobre autismo. Cadernos da Escola de Educação e Humanidades, Curitiba, v. 1, n. 11, 25-39, 2016. Disponível em: https://www.academia.edu/31070412/Uma_breve_introdu\%C3\%A7\%C3\%A3o_ sobre_o_autismo. Acesso em: 11 fev. 2020. 
ZAIKIEVICZ, A. P. A educação infantil e seu cotidiano: ouvindo o que dizem as crianças da pré-escola sobre a instituição educativa. 2017. 178f. Dissertação (Mestrado em Educação) - Programa de Pós-Graduação em Educação, Universidade Católica Dom Bosco, Campo Grande, 2017.

\section{SOBRE AS AUTORAS}

Lyanny Araujo Francês é mestre em currículo e gestão da escola básica pela Universidade Federal do Pará (UFPA). Professora do Centro de Referência em Inclusão Educacional Gabriel Lima Mendes (CRIE).

E-mail: lyanny.araujo@gmail.com

Amélia Maria Araújo Mesquita é doutora em educação pela Universidade Federal do Pará (UFPA). Professora da mesma instituição. E-mail:amelia.mesquita05@gmail.com

Conflitos de interesse: Os autores declaram que não possuem nenhum interesse comercial ou associativo que represente conflito de interesses em relação ao manuscrito.

Financiamento: $\mathrm{O}$ estudo não recebeu financiamento.

Contribuições dos autores: Administração do Projeto, Análise Formal, Conceituação, Curadoria de Dados, Escrita — Primeira Redação, Investigação, Metodologia, Obtenção de Financiamento, Recursos, Software, Supervisão, Validação e Visualização: Francês, L.A; Mesquita, A.M.A.

Recebido em 15 de abril de 2020 Aprovado em 24 de agosto de 2020 